\title{
COMPARISON OF CLOPIDOGREL AND ACETOSAL IN THE PREVENTION OF RECCURENT ISCHEMIC STROKE AT DR. MOEWARDI REGIONAL GENERAL HOSPITAL
}

\author{
ANIS DWI KRISTIYOWATI ${ }^{1}$, RETNOSARI ANDRAJATI ${ }^{1}$, ANTON BAHTIAR $^{2 *}$ \\ ${ }^{1}$ Department of Clinical Pharmacy, Faculty of Pharmacy, Universitas Indonesia, Kampus Baru UI, Depok 16424, Indonesia. ${ }^{2}$ Department of \\ Pharmacology and Toxicology, Faculty of Pharmacy, Universitas Indonesia, Kampus Baru UI, Depok 16424, Indonesia. \\ Email: anton.bahtiar@gmail.com \\ Received: 12 May 2017, Revised and Accepted: 17 June 2017
}

ABSTRACT

Objective: This study was conducted to determine the effect of clopidogrel on the prevention of recurrent stroke.

Methods: This study used case-control study; data were taken from patient's medical record of DR. Moewardi Regional General Hospital in the period of January 2013 - February 2017. Case group is a recurrent stroke patient receiving an acetosal or clopidogrel. The control group is a nonrecurrent stroke patient who receives an acetosal or clopidogrel.

Results: During the period of study, the number of medical sample record data are 177 samples from the entire study subjects that met the inclusion and exclusion criteria, 50 medical records entered as subject of case study, 32 medical record samples was excluded because medical record data at the first stroke was gone (obselete), 35 medical record was excluded because medical record data at first stroke was not at of DR. Moewardi Regional General Hospital, 4 samples of medical records was excluded for using a combination of acetosal and clopidogrel, 55 samples of medical records as control subjects. Patients who use clopidogrel have a tendency to prevent recurrent stroke, but statistically not significantly different. This study shows that men tend to suffer more recurrent ischemic stroke (64.0\%) than women. While in the control group of recurrent ischemic stroke of women (56.4\%) more experienced the first stroke than men. Patients who had a stroke almost all had a history of hypertension (90.2\%). Recurrent stroke patients in this study almost all had a history of hypertension. Bivariate analysis was showed that gender, history of diabetes mellitus (DM) and history of hypertension had an effect on recurrent stroke events. From the multivariate analysis, it was found that men had a risk of 2.328 for recurrent stroke ( $\mathrm{p}=0.047$ ), the history of DM had a risk of 3.975 times for recurrent stroke ( $\mathrm{p}=0.016)$ and history of hypertension was 4.021 times for recurrent stroke ( $\mathrm{p}=0.03)$.

Conclusion: Clopidogrel has no effect on recurrent stroke. Male, history of DM and hypertension has an effect on recurrent stroke events.

Keywords: Recurrent stroke, Clopidogrel, Medical record, Case-control.

(C) 2017 The Authors. Published by Innovare Academic Sciences Pvt Ltd. This is an open access article under the CC BY license (http://creativecommons. org/licenses/by/4. 0/) DOI: http://dx.doi.org/10.22159/ajpcr.2017.v10i10.19893

\section{INTRODUCTION}

Stroke is the leading cause of disability. In the developed world countries, stroke is the third cause of death [1]. There is an increase in stroke prevalence from $8.3 / 1000$ population to $12.1 / 1000$ population. The prevalence of stroke in Indonesia based on diagnosis by health worker is 7.0 per mile and based on diagnosis by health worker or with symptoms 12.1 per mile. The prevalence of stroke is similar in males and females. The prevalence of stroke in Central Java increased from 5.70/00 (2007) to 7.70/00 (2013) (based on diagnosis by health worker) and 7.6\% (2007) to 12.30/00 (2013) [2].

Each year approximately 795,000 people suffer from the first stroke or recurrent stroke. Approximately, 610,000 of them for the first stroke and 185,000 for recurrent stroke [3]. A recurrent stroke probability after the first stroke is more than $3 \%$ to $10 \%$ in the $1^{\text {st }}$ month and $5 \%$ to $14 \%$ in the $1^{\text {st }}$ year [1]. Research in Singapore showed a recurrent stroke risk is $18.4 \%$ after 5 years of the first stroke. Male patients have a higher risk and increased mortality in ischemic stroke [4].

Four antiplatelet drugs have been approved by the Food and Drug Administration (FDA) for prevention of vascular events among patients with a stroke or transient ischmeic attack (TIA): Aspirin, combination aspirin/dipyridamole, clopidogrel, and ticlopidine. On average, these agents reduce the relative risk of stroke, myocardial infarction (MI) or death by about $22 \%$ [5]. Antiplatelet therapy is an antithrombotic cornerstone for ischemic secondary prevention and should be used in noncardioembolic stroke therapy. The antiplatelet agents currently used are acetosal, clopidogrel, and acetosal plus extended release dipyridamole American Stroke Association (ERDP-ASA), which is the first-line antiplatelet agent [6]. Clopidogrel is superior to acetosal in preventing death and cardiovascular events after acute noncardioembolic stroke ischemic [7]. Clopidogrel proven as a safe and effective drug for the prevention of secondary vascular events in Clopidogrel Versus Acetosal in Patients at Risk of Ischaemic Received Events (CAPRIE) study, where the benefits of clopidogrel better than acetosal in the prevention of vascular events with a relative risk (RR) reduction $8.7 \%$ [8]. Acetosal is the most widely used antiplatelet agent, which according to the study can reduce the RR of recurrent vascular events from $22 \%$ to $13 \%$ and the risk of recurrent stroke by $15 \%$ compared with placebo [1]

\section{METHODS}

\section{Materials}

Medical records of JKN (National Health Insurance) patients with diagnosis of ischemic stroke in the inpatient room of Dr. Moewardi Regional General Hospital in the period of January 2013 - February 2017 using clopidogrel and using other than clopidogrel (acetosal), medical records of recurrent ischemic stroke patients, with the previous stroke (first stroke) treated at Dr. Moewardi Regional General Hospital.

\section{Methods}

The selected research design is case-control study. Retrospective data retrieval was performed through patient medical records with recurrent ischemic stroke using clopidogrel and using other than clopidogrel 
(acetosal) in inpatient room of Dr. Moewardi Regional General Hospital in the period of January 2013 - February 2017.

\section{RESULTS}

During the period of study, the number of medical sample record data are 177 samples from the entire study subjects that met the inclusion and exclusion criteria, 50 medical records entered as subject of case study, 32 medical record samples were excluded because medical record data at the first stroke were gone (obselete), 35 medical record was excluded because medical record data at first stroke was not at of Dr. Moewardi Regional General Hospital, 4 samples of medical records was excluded for using a combination of acetosal and clopidogrel, 55 samples of medical records as control subjects. Characteristics of study subjects including age and sex. Characteristic of subject study can be seen in Table 1 and frequency types of complications of disease can be seen in Table 2 .

Table 1: Distribution of characteristic frequency and disease in clopidogrel patients and patients of asetosal users at Dr. Moewardi Regional General Hospital, January 2013 to February 2017

\begin{tabular}{|c|c|c|c|}
\hline \multirow[t]{2}{*}{ S. No. } & \multirow[t]{2}{*}{ Variable } & \multicolumn{2}{|l|}{ n (\%) } \\
\hline & & Case & Control \\
\hline \multirow[t]{3}{*}{1} & Age (years) & & \\
\hline & $18-59$ & $24(48.0)$ & $31(56.4)$ \\
\hline & $\geq 60$ & $26(52.0)$ & $24(43.6)$ \\
\hline \multirow[t]{3}{*}{2} & Gender & & \\
\hline & Male & $32(64.0)$ & $24(43.6)$ \\
\hline & Female & $18(36.0)$ & $31(56.4)$ \\
\hline \multirow[t]{3}{*}{3} & Antiplatelet usage & & \\
\hline & Clopidogrel & $16(32.0)$ & $21(38.2)$ \\
\hline & Asetosal & $34(68.0)$ & $34(61.8)$ \\
\hline \multirow[t]{3}{*}{4} & Hypertension history & & \\
\hline & Yes & $46(90.2)$ & $42(76.4)$ \\
\hline & No & $4(8.0)$ & $13(23.6)$ \\
\hline \multirow[t]{3}{*}{5} & DM & & \\
\hline & Yes & $15(30.0)$ & $7(12.7)$ \\
\hline & No & $35(70.0)$ & $48(87.3)$ \\
\hline \multirow[t]{3}{*}{6} & Hypercolesterolemia history & & \\
\hline & Yes & $6(12.0)$ & $4(7.3)$ \\
\hline & No & $44(88.0)$ & $51(92.7)$ \\
\hline \multirow[t]{3}{*}{7} & Heart disease history & & \\
\hline & Yes & $14(28.0)$ & $12(21.8)$ \\
\hline & No & $36(72.0)$ & $43(78.2)$ \\
\hline \multirow[t]{3}{*}{8} & Period of sick (months) & & \\
\hline & $<3$ & $12(24.0)$ & - \\
\hline & $\geq 3$ & $38(76.0)$ & - \\
\hline
\end{tabular}

DM: Diabetes mellitus
The goal of stroke management, in general, is to reduce morbidity and reduce mortality and decrease disability rates. One of the most important attempts to achieve this goal is the early recognition of stroke symptoms and early stroke management starting with rapid and precise pretrial handling. The use of antihypertensive drugs, antidiabetes melitus, antihiperkolerterol, and cardiovascular drugs in patients with ischemic stroke in inpatient at Dr. Moewardi Regional General Hospital can be seen in Table 3.

The American Heart Association (AHA) and the ASA published guidelines to prevent recurrent stroke in patients who have had a previous stroke or TIA. Guidelines for modifying recurrent stroke risk factors include treatable vascular risk factors and modifiable behavioral risk factors, and antithrombotic use (antiplatelet, oral anticoagulant) [9]. Four antiplatelet drugs have been approved by the US FDA to prevent vascular events in patients with stroke or TIA: Acetosal, ticlopidine, clopidogrel, and combinations of acetosal/dipyridamole. On average, antiplatelet agents have been shown to reduce the RR of stroke, MI, About 22\% [5]. In this study, used 2 antiplatelet are asetosal and clopidogrel. To see the effect of using clopidogrel with acetosal on prevention of recurrent stroke can be seen in Table 4 .

Result of research was conducted at Dr. Moewardi Regional General Hospital, in recurrent ischemic stroke patients where at first stroke using antiplatelet therapy clopidogrel or asetosal can be seen in Table 4. These data were obtained from the medical records of stroke nonhemorrhagic stroke patients from January 2013 to February 2017. Clopidogrel had a risk in preventing recurrent stroke with odds ratio $(O R)=0.76$. However, statistically did not differ significantly $(p=0.508)$.

The effect of confounding variables on recurrent stroke events can be seen in Table 5 to determine the effect of confounding variables on the incidence of recurrent stroke Chi-square test to show the magnitude of risk. The magnitude of influence is expressed by the OR for bivariate analysis. The value of $\mathrm{OR}>1$ and the trust range does not include the number 1 , meaning that the variable is considered a risk factor. The meaning limit is when $\mathrm{P} \leq 0.05$ with $95 \%$ confidence interval (CI).

Confounding variables that are recurrent risk factors for stroke are history of hypertension, history of diabetes, history of hypercholesterolemia, history of heart disease and sex. However, statistically significant between case and control groups was the presence of a history of diabetes and sex.

\section{Age}

The study showed that the number of patients aged 18-59 years had a smaller risk for recurrent stroke compared to age $\geq 60$ years. The $p$ value in the analysis of age relationship with recurrent stroke incidence was 0.437 ( $p>0.05$ ), so it showed that there was no significant relationship between age and recurrent stroke incidence.

Table 2: Frequency types of complications of disease in recurrent ischemic stroke patients at Dr. Moewardi Regional General Hospital, the period January 1, 2013 to February 2017

\begin{tabular}{|c|c|c|c|}
\hline S. No. & Jenis komplikasi penyakit & Number of cases & Number of control \\
\hline 1 & No complication & 0 & 10 \\
\hline 2 & Hypertension & 23 & 27 \\
\hline 3 & $\mathrm{DM}$ & 2 & 1 \\
\hline 4 & Hypertension + DM & 7 & 3 \\
\hline 5 & Hypertension + hypercholesterol & 4 & 2 \\
\hline 6 & Heart disease & 0 & 1 \\
\hline 7 & Hypertension + heart disease & 7 & 7 \\
\hline 9 & Hypertension + DM + heart & 4 & 1 \\
\hline 10 & Hypercholesterol + heart disease & 1 & 0 \\
\hline 11 & Hypertension + hypercholesterol + heart disease & 0 & 1 \\
\hline 12 & Hypertension + DM+hypercholesterol + heart disease & 1 & 1 \\
\hline
\end{tabular}

DM: Diabetes mellitus 
Gender

Based on the results of this study, men have 2.296 times the risk of recurrent stroke. The results of the analysis found a significant relationship between gender with recurrent stroke incidence with the value $\mathrm{p}=0.05\left({ }^{*} \mathrm{p} \leq 0.05\right)$.

\section{Hypertension history}

The result of analysis of correlation between history of hypertension with recurrent stroke incidence showed that patient with a history of hypertension had a risk of recurrent stroke 3.560 times. The association between history of hypertension and recurrent stroke incidence was statistically significant with $\mathrm{p}=0.03\left({ }^{*} \mathrm{p} \leq 0.05\right)$.

Table 3: Distribution of frequency of drug usage of clopidogrel user, asetosal user patient at Dr. Moewardi Regional General Hospital, the period January 2013 to February 2017

\begin{tabular}{llll}
\hline S. No. & Variable & $\mathbf{n}(\mathbf{\%})$ & \\
\cline { 3 - 4 } & & Case & Control \\
\hline 1 & Hypertension therapy & & \\
& Yes & $35(70.0)$ & $28(50.9)$ \\
& No & $15(30.0)$ & $27(49.1)$ \\
2 & DM therapy & $13(26.0)$ & $10(18.2)$ \\
& Yes & $37(74.0)$ & $45(81.8)$ \\
& No & & \\
& Hypercholesterol therapy & $24(48.0)$ & $19(34.5)$ \\
& Yes & $26(52.0)$ & $36(65.5)$ \\
& No & & $7(12.7)$ \\
& Heart disease therapy & $14(28.0)$ & $48(87.3)$ \\
\hline
\end{tabular}

DM: Diabetes mellitus

Table 4: The effect of clopidogrel or acetosal antiplatelet use on the prevention of recurrent stroke occurrence at Dr. Moewardi Regional General Hospital, January 2013 to February 2017

\begin{tabular}{lllll}
\hline Variable & $\mathbf{n}(\mathbf{\%})$ & p & OR \\
\cline { 2 - 5 } & Kasus & Kontrol & & \\
\hline Using antiplatelet clopidogrel & $16(32.0)$ & $21(38.2)$ & 0.508 & 0.762 \\
Not using clopidogrel (asetosal) & $34(68.0)$ & $34(61.8)$ & $0.340-1.705$ \\
\hline
\end{tabular}

OR: Odds ratio, CI: Confidence interval

Table 5: The effect of confounding variables against the prevention of recurrent stroke occurrences

\begin{tabular}{|c|c|c|c|c|c|}
\hline \multirow[t]{2}{*}{ Variable } & \multicolumn{2}{|l|}{ n (\%) } & \multirow[t]{2}{*}{$\mathbf{p}$} & \multirow[t]{2}{*}{ OR } & \multirow[t]{2}{*}{$95 \% \mathrm{CI}$} \\
\hline & Case & Control & & & \\
\hline \multicolumn{6}{|l|}{ Gender } \\
\hline Male & $32(64.0)$ & $24(43.6)$ & 0.05 & 2.296 & $1.047-5.038$ \\
\hline Female & $18(36.0)$ & $31(56.4)$ & & & \\
\hline \multicolumn{6}{|l|}{ Age (years) } \\
\hline $18-59$ & $24(48.0)$ & $31(56.4)$ & 0.437 & 0.715 & $0.331-1.542$ \\
\hline$\geq 60$ & $26(52.0)$ & $24(43.6)$ & & & \\
\hline \multicolumn{6}{|l|}{ Antiplatelet theraphy } \\
\hline Using clopidogrel & $16(32.0)$ & $21(38.2)$ & 0.715 & 0.74 & $0.331-1.653$ \\
\hline Not using clopidogrel (asetosal) & $34(68.0)$ & $34(61.8)$ & & & \\
\hline \multicolumn{6}{|l|}{ Hypertension history } \\
\hline Yes & $46(90.2)$ & $42(76.4)$ & 0.03 & 3.560 & $1.076-11.773$ \\
\hline No & $4(9.8)$ & $13(23.6)$ & & & \\
\hline \multicolumn{6}{|l|}{ DM history } \\
\hline Yes & $15(30.0)$ & $7(12.7)$ & 0.03 & 2.939 & $1.084-7.967$ \\
\hline Yes & $6(12.0)$ & $4(7.3)$ & 0.410 & 1.739 & $0.461-6.560$ \\
\hline No & $44(88.0)$ & $51(92.7)$ & & & \\
\hline \multicolumn{6}{|l|}{ Heart disease history } \\
\hline Yes & $14(28.0)$ & $12(21.8)$ & 0.464 & 1.394 & $0.573-3.390$ \\
\hline No & $36(72.0)$ & $43(78.2)$ & & & \\
\hline
\end{tabular}

OR: Odds ratio, CI: Confidence interval, DM: Diabetes mellitus 
Table 6: Multivariate logistic regression test result influence of clopidogrel, history of DM, hypertension and sex on prevention of recurrent stroke occurrence at Dr. Moewardi Regional General Hospital, January 2013 to February 2017

\begin{tabular}{llll}
\hline Variables & OR & $\mathbf{p}$ & $\mathbf{9 5 \%}$ CI \\
\hline DM history & 3.975 & 0.016 & $1.298-12.170$ \\
Gender & 2.328 & 0.047 & $1.010-5.367$ \\
Hypertension history & 4.021 & 0.030 & $1.142-14.162$ \\
\hline
\end{tabular}

OR: Odds ratio, CI: Confidence interval, DM: Diabetes mellitus

\section{DISCUSSION}

Characteristics of age-based samples included in the inclusion criteria in this study were adult patients aged from 18 years. The division of this group is based on a group of adult nonelderly and elderly patients. This study shows that recurrent ischemic stroke cases are slightly more prevalent at age over 60 years $(52.0 \%)$. While on control of ischemic stroke is not repeated (first stroke) more occur at age 18-59 years (56.4\%).

This study shows that men tend to suffer more recurrent ischemic stroke $(64.0 \%)$ than women. While in the control group of recurrent ischemic stroke of women (56.4\%) more experienced the first stroke than men. This study is in accordance with research conducted by Siswanto that the incidence of recurrent stroke more experienced by men [9].

Patients who had had a stroke almost all had a history of hypertension (90.2\%). Recurrent stroke patients in this study almost all had a history of hypertension. Similarly, in the control group, in which more stroke patients had a history of hypertension $(76.4 \%)$ than those who did not have a history of hypertension.

According to a British study of TIA, there is a relationship between blood pressure and recurrent stroke. Data suggest that a drop in diastolic pressure of $5 \mathrm{mmHg}$ is associated with a decreased risk of a third of stroke events [10].

The number of patients who had a history of hypercholesterolemia in both case and control groups was fewer. Stroke patients in both recurrent and nonrecurring groups had a history of DM. This is not consistent with studies in the CAPRIE study where patients with DM more in patients with ischemic stroke [11].

This study showed that the number of patients with a history of heart disease was lower in both case and control groups. This is consistent with a study conducted by Moroney et al., in which fewer recurrent stroke patients had a history of heart disease [12].

The time interval between the first stroke and recurrent stroke in this study revealed that larger recurrent strokes occurred over 3 months after the first stroke. This is consistent with a study conducted by Moroney et al. that more recurrent strokes occur early in the 90 days after the first stroke compared to 30 days after the first stroke [12].

This study showed that more patients were taking hypertension drugs than those who did not use hypertension drugs in both case and control groups. While the use of drugs diabetes melitus, hypercholesterol drugs and cardiovascular drugs are less used both in case and control groups.

The risk of secondary vessel disease has been shown to decrease with the treatment of hypertension, hypercholesterolemia, and antiplatelet drug therapy [13]. In general, hypertension is the most significant risk factor for stroke, both ischemic and hemorrhagic. Increased blood pressure plays an important role in the development of vascular disease, including coronary heart disease, heart failure, aortic atherosclerosis, cerebral arteries, and small occlusion. Controlling blood pressure reduces the risk of coronary disease and stroke. A meta-analysis of randomized controlled trials of antihypertensive therapy after stroke or TIA decreased recurrence of stroke (RR=0.76; 95\% CI 0.63-0.92) [13].

Stroke (especially ischemic stroke, not hemorrhagic stroke) is a form of hypertension associated with organ damage. Achieving a target of blood pressure reduction in patients with ischemic stroke is considered a major modality to reduce the risk of stroke [6]. Hypertension is a major risk factor for the occurrence of the first stroke or the next stroke [14]. Achieving a target of blood pressure reduction is essential to reduce cardiovascular events in hypertensive patients [15]. Hypertension therapy is used to lower blood pressure and prevent the complications of other diseases associated with high blood pressure [16].

This study showed that recurrent stroke incidence in the group taking antiplatelet clopidogrel therapy was less than the group using the antiplatelet therapy of $32 \%$ and $68.0 \%$. While in the control group using klopidogrel $38.2 \%$ and who use the assetosal $61.8 \%$. Patients taking antiplatelet clopidogrel therapy showed an OR of 0.762 . This means that klopidogrel prevents recurrent stroke events. However, statistically the results were not significantly different $(\mathrm{OR}=0.762,95 \%$ CI $0.340-1.705, p>0.05$ ) so that clopidogrel is not better in preventing recurrent stroke incidence compared to acetosal in RSUD Dr. Moewardi Surakarta. This is not in accordance with research in the CAPRIE study where the results obtained that klopidogrel more effective than asetosal in reducing the risk of ischemic stroke, MI, and vascular death [11]. This is probably due to differences in therapeutic responses due to differences in the characteristics of the research samples that the researchers did with the samples in the CAPRIE study, and the sample studies were less numerous.

Antiplatelet agents have been shown to reduce the RR of stroke, MI about $22 \%$ [5]. Clopidogrel proved to be a safe and effective drug for the prevention of secondary vascular events in CAPRIE study. These trials, the benefits of clopidogrel are better than those for acetosal prevention of vascular events with a RR reduction of 8.7\% [8]. A large multinational test (prevention regimen for effectively avoiding second strokes) that compares acetosal plus ERDP with clopidogrel to the risk of recurrent stroke is no different for both antiplatelets, but a better tolerance clopidogrel where less bleeding and headache occur [17]. Clopidogrel is superior to acetosal in preventing death and cardiovascular events after acute noncardioembolic stroke ischemic [18].

Clopidogrel acts on platelets irreversibly by binding to adenosine diphosphate (ADP) receptors, blocking the activation of ADPdependent activation of the glycoprotein IIb-IIIa complex. This complex acts as a fibrinogen receptor on the platelet surface. Clopidogrel is a P2Y12 receptor antagonist, inhibiting platelet aggregation [19]. The AHA/ASA and American College of Chest Physicians guidelines recommend a daily dose of clopidogrel for secondary stroke prevention is $75 \mathrm{mg}$ [20]. Clopidogrel should be metabolized first by the cytochrome P450 (CYP450) enzyme to produce an active metabolite. Genetic polymorphism CYP450 2C19 causes decreased active metabolites, pharmacokinetic karaketristik differences, and decreases clinical response in patients with poor metabolizers [21]. Patients with high on-treatment platelet reactivity or genetic variations, such as CYP 2C19 loss-of-function alleles, have an increased risk of ischemic events, particularly stent thrombosis. Ethnic groups, with a higher frequency of single nucleotide polymorphisms responsible for clopidogrel resistance, may be benefited from prior genetic testing [22]. Clopidogrel's safety equals to acetosal on moderate doses and is safer than that of teclopidine. It is profitable based on benefit/security ratios. Clopidogrel is an effective antiplatelet agent for use in atherothrombotic disease. According to the study, clopidogrel (CAPRIE) study was superior to acetosal with a RR reduction of stroke incidence of $7.3 \%$, mean annual incidence rate of stroke in clopidogrel group was $7.15 \%$ compared to $7.71 \%$ [11]. Research profile of hemostasis between clopidogrel and assetosal did not show any significant difference (PT, aPTT and INR). Administration of DLBS1033 at a dose of $3 \mathrm{mg} \times 490 \mathrm{mg}$ 
daily for 90 days on ischemic stroke subjects is safe and comparable to aspirin $80 \mathrm{mg}$ daily or clopidogrel $75 \mathrm{mg}$ daily. There are no significant parameters of hemostasis parameters. No adverse events of bleeding in any group were observed during the study [23].

The occurrence of recurrent stroke is influenced by many factors not only influenced by antioplatelet delivery factor. Therefore, this study also performed the analysis of confounding variables as a recurrent stroke risk factor in both study groups. Confounding variables that are recurrent risk factors for stroke are history of hypertension, history of diabetes, history of hypercholesterolemia, history of heart disease and sex. However, statistically significant between case and control groups was the presence of a history of diabetes and sex.

The age variable in this study showed that there was no significant correlation between age and recurrent stroke incidence. These results are consistent with the research conducted by Burn et al. [24], i.e., the risk of recurrent stroke seems to have no association with age, but age is a prognostic factor in recurrent stroke of 75-84 years [25].

Based on the results of this study, men had a risk of 2296 repeated stroke events, statistically significant. This is not in accordance with the research by Burn et al. that there is no increased risk of recurrent stroke in men [24].

The history of hypertension has a risk of recurrent stroke 3.560 times, statistically significant $\left({ }^{*} p \leq 0,05\right)$. This is in accordance with research conducted Burn et al. that hypertension increases the risk of recurrent stroke 1.01 times [24]. Thomas et al.'s study also showed similar results that hypertension increased the risk of recurrent stroke 1.40 times [26].

Acute hypertension is an increase in blood pressure above normal values and is the initial premorbid which occurs within the first $24 \mathrm{hrs}$ of symptom onset in stroke patients. This phenomenon is reported in $>60 \%$ of patients with stroke in a representative national study of the United States [27].

Increased blood pressure is associated with increased intracranial pressure (ICP), especially in the presence of brainstem compression. Where it has particular relevance for patients with intracerebral and subarachnoid hemorrhage. Increased ICP can lead to increased blood pressure. However, high blood pressure does not clearly show brain ischemia. This suggests that a major cause of acute hypertensive responses is the damage or compression of certain regions of the brain that mediate autonomic control [27].

This study showed that the history of DM had a risk of 2.939 times the incidence of recurrent stroke, statistically significant. This is consistent with the study conducted by Zavoreo patients with DM had a 1.5-3 stroke risk compared with patients with no history of DM related to increased mortality and morbidity of the disease [28]. In accordance with the results of the CAPRIE study in which DM increased the risk of ischemic stroke more than 3-fold compared with no DM [11]. The condition of hyperglycemia can increase stroke severity and also worsen the clinical outcome of stroke [29].

The results of this study indicate that the history of hypercholesterolemia has a risk of 1.700 times the incidence of recurrent stroke is not statistically significant. This is not consistent with studies in the CAPRIE study that hypercholesterolemia increases the risk of ischemic stroke 4-fold higher [11]. Hyperlipidemia is not a potential risk factor for stroke when compared with the risk of heart disease. Although, the risk of stroke decreases with the use of statins in patients with coronary artery disease [13].

Confounder variables (male gender, history of hypertension, history of DM) were done multivariate analysis showed three variables that have an effect on the occurrence of repetitive stroke that is gender and history of DM and history of hypertension. This study shows that men have a higher risk for recurrent stroke than women. This is not consistent with the research by Burn et al. that there is no increased risk of recurrent stroke in men [24]. A history of DM and a history of hypertension also had an effect on recurrent stroke events. This study is in accordance with research conducted by Spurthi, et al. the main risk factor in stroke patients is hypertension followed by diabetes [30]. And also this study is in accordance with research conducted by Vurumadla et al. that the risk factors associated with stroke is hypertension followed by diabetes [31].

The percentage of occurrence of recurrent stroke after the first major stroke occurred in patients with cardiac complications with cholesterol $(100 \%)$, complications of hypertension, DM with heart $(80 \%)$, complication history of hypertension with DM (70\%), and history of DM (66.7\%). The percentage of recurrent stroke in people with DM $(66,7 \%)$ is bigger than in hypertension patient $(46 \%)$.

\section{CONCLUSION}

Clopidogrel has no effect on recurrent stroke. Male and history of DM, history of hypertension have an effect on recurrent stroke events.

\section{REFERENCES}

1. Gouya G, Arrich J, Wolzt M, Huber K, Verheugt FW, Gurbel PA, et al. Antiplatelet treatment for prevention of cerebrovascular events in patients with vascular diseases: A systematic review and meta-analysis. Stroke 2014;45:492-503.

2. Ministry of Health Republics of Indonesia. Basic Health Researh 2013. Jakarta: Kementerian Kesehatan Republik Indonesia; 2013.

3. Mozaffarian D, Benjamin EJ, Go AS, Arnett DK, Blaha MJ, Cushman M, et al. AHA Statistical Update heart disease and stroke statistics - 2016 update A report from the American Heart Association. Circulation 2015; 132:e2-323.

4. Sun Y, Lee SH, Heng BH, Chin VS 5-year survival and rehospitalization due to stroke recurrence among patients with hemorrhagic or ischemic strokes in Singapore. BMC Neurol 2013;13:133.

5. Furie KL, Kasner SE, Adams RJ, Albers GW, Bush RL, Fagan SC, et al. Guidelines for the prevention of stroke in patients with stroke or transient ischemic attack: A guideline for healthcare professionals from the american heart association/american stroke association. Stroke 2011;42:227-76.

6. Joseph TD. Pharmacotherapy: A Pathophysiologyc Approach. $8^{\text {th }}$ ed. In New York: McGraw Hill; 2011. p. 353-60.

7. Goldstein LB, Bushnell CD, Adams RJ, Appel LJ, Braun LT, Chaturvedi $\mathrm{S}$, et al. Guidelines for the primary prevention of stroke: A guideline for healthcare professionals from the American Heart Association/American Stroke Association. Stroke 2011;42:517-84.

8. Albers GW, Amarenco P. Combination therapy with clopidogrel and aspirin: Can the CURE results be extrapolated to cerebrovascula patients? Stroke 2001;32:2948-9.

9. Siswanto Y. Some Risk Factors Affecting Recurrent Stroke Occurrences: A Case Study at Kariadi Hospital Semarang. Diponegoro of University; 2005.

10. Hewitt J, Castilla Guerra L, Fernández-Moreno Mdel C, Sierra C. Diabetes and stroke prevention: A review. Stroke Res Treat 2012;2012:673187.

11. CAPRIE Steering Committee. A randomised, blinded, trial of clopidogrel versus aspirin in patients at risk of ischaemic events (CAPRIE). CAPRIE Steering Committee. Lancet 1996;348:1329-39.

12. Moroney JT, Bagiella E, Paik MC, Sacco RL, Desmond DW. Risk factors for early recurrence after ischemic stroke: The role of stroke syndrome and subtype. Stroke 1998;29:2118-24.

13. Silva GS, Koroshetz WJ, González RG, Schwamm LH. Causes of ischemic stroke. In: Acute Ischemic Stroke Imaging and Intervention. Vol. 8. Brazil: Springer-Verlag Berlin Heidelberg; 2011. p. 25-42.

14. National Heart Foundation of Australia. Guideline for the diagnosis and management of hypertension in adults. In: Guideline for the Diagnosis and managemnet of Hypertension in Adults 2016. Melbourne: National Heart Foundation of Australia; 2016.

15. U.S Department of Health and Human Services. The Seventh Report of the Joint National Committee on Prevention, Detection, Evaluation, and Treatment High Blood Pressure: Seventh. Boston: NIH Publication; 2004.

16. Dennison-Himmelfarb C, Handler J, Lackland DT. 2014 evidencebased guideline for the management of high blood pressure in adults 
report from the panel members appointed to the eighth Joint National Committee (JNC 8). Clin Rev 2014;1097:1-14.

17. Sacco RL, Diener HC, Yusuf S, Cotton D, Ounpuu S, Lawton WA, et al. Aspirin and extended-release dipyridamole versus clopidogrel for recurrent stroke. N Engl J Med 2008;359:1238-51.

18. Milionis HJ, Gerotziafas G, Kostapanos MS, Vemmou A, Zis P, Spengos $\mathrm{K}$, et al. Clopidogrel vs. aspirin treatment on admission improves 5-year survival after a first-ever acute ischemic stroke. data from the Athens Stroke Outcome Project. Arch Med Res 2011;42:443-50

19. Vyasa BM, Dave R, Daniel P, Anand I, Patel C. A view on combination antiplatelet agents in ischemic stroke. India J Clin Pract 2013;23(11):701-6.

20. Shiau Y, Hu C, Chiueh CC. Journal of experimental and clinical medicine preventive effectiveness of aspirin on recurrent stroke. J Exp Clin Med (Elsevier Taiwan LLC) 2012;4(4):203-8.

21. Clark MA, Finkel R, Rey JA, dan Whalen K. Pharmacology. $5^{\text {th }}$ ed. Philadelphia: Lippincont Williams\&Wilkins; 2012.

22. Bashir S, Poornima R. Pharmaocogenetic variations related to clopiodogrel resistance and its clinical implications: An issue which remains largely unaddressed. Asian J Pharm Clin Res 2016;9(5):12-4.

23. Setyopranoto I, Wibowo S, Tjandrawinata RR. Hemostasis profile and clinical outcome of acute ischemic stroke patients treated with oral lumbrokinase DLBS1033: A comparative study versus aspirin and clopidogrel. Asian J Pharm Clin Res 2016;9(1):186-92.

24. Burn J, Dennis M, Bamford J, Sandercock P, Wade D, Warlow C. Longterm risk of recurrent stroke after a first-ever stroke. The Oxfordshire Community Stroke Project. Stroke 1994;25:333-7.

25. Hankey GJ, Jamrozik K, Broadhurst RJ, Forbes S, Burvill PW, Anderson CS, et al. Long-term risk of first recurrent stroke in the Perth Community Stroke Study. Stroke 1998;29:2491-500.

26. Hillen T, Coshall C, Tilling K, Rudd AG, McGovern R, Wolfe CD; South London Stroke Register. Cause of stroke recurrence is multifactorial: Patterns, risk factors, and outcomes of stroke recurrence in the South London Stroke Register. Stroke 2003;34:1457-63.

27. Qureshi AI. Contemporary reviews in cardiovascular medicine acute hypertensive response in patients with stroke pathophysiology and management. Circulation 2008;118:176-87.

28. Zavoreo I. Hyperglycemia and stroke. Period Biol 2012;114(3):269-75.

29. Jørgensen H, Nakayama H, Raaschou HO, Olsen TS. Stroke in patients with diabetes. The Copenhagen Stroke Study. Stroke 1994;25:1977-84.

30. Spurthi T, Gowthami B, Khyathi D, Vinod G. Risk elements and drug utilization in stroke patients. Int J Pharm Pharm Sci 2016;8(10):8-10.

31. Vurumadla S, Rakshith VM, Venkateswarlu K. A study on symptoms, risk factors and prescribing pattern of drugs used in stroke. Int J Pharm Pharm Sci 2014;7(1):421-6. 